\title{
A governança do setor espacial brasileiro: a AEB no exercício do Centro Estratégico do Sindae
}

\author{
Fabiany Maria Made e Vellasco ${ }^{1}$ \\ Henrique Fernandes Nascimento ${ }^{2}$ \\ ${ }^{1}$ Ministério da Cidadania, Brasília - DF, Brasil \\ ${ }^{2}$ Agência Espacial Brasileira (AEB), Brasília - DF, Brasil
}

O objetivo principal deste artigo foi analisar, à luz da teoria institucionalista, a influência do papel da Agência Espacial Brasileira (AEB) enquanto coordenadora-geral do Sistema Nacional de Desenvolvimento das Atividades Espaciais (Sindae) nos resultados da implementação do Programa Nacional de Atividades Espaciais (Pnae), no período de 1996 a 2018. Para desenvolver a pesquisa, optou-se pela abordagem de estudo de caso, com a triangulação de diferentes fontes de dados, tais como: leis e normas gerais; publicações acadêmicas e técnicas; e entrevistas formais. Os principais resultados encontrados apontam para: uma concentração de poder nos institutos de pesquisa; uma inversão de papéis entre institutos de pesquisa e empresas dentro do Pnae; e a necessidade de fortalecer o papel da AEB como centro estratégico do Sindae. O centro estratégico de governança do Sindae tem papel fundamental na promoção de incentivos para a participação dos diferentes atores que o compõem. Assim, é preciso que a AEB coordene os esforços entre organizações para propiciar a adequada atuação de cada uma delas e uma implementação bem-sucedida do Pnae.

Palavras-chave: governança, centro estratégico, setor espacial 


\section{La gobernanza del sector espacial brasileño: AEB en el ejercicio del Centro Estratégico de Sindae}

El objetivo principal de este artículo fue analizar, a la luz de la teoría institucionalista, la influencia del rol de la Agencia Espacial Brasileña (AEB) como coordinadora general del Sistema Nacional de Desarrollo de Actividades Espaciales (Sindae) en los resultados de la implementación del Programa Nacional de Actividades Espaciales (PNAE), de 1996 a 2018. Para desarrollar la investigación, optamos por el enfoque de estudio de caso, con la triangulación de diferentes fuentes de datos, tales como: leyes y normas generales; publicaciones académicas y técnicas; y entrevistas formales. Los principales resultados encontrados apuntan a: una concentración de poder en los institutos de investigación; un cambio de roles entre institutos de investigación y empresas dentro del PNAE; y la necesidad de fortalecer el papel de AEB como centro estratégico del Sindae. El centro estratégico de la gobernanza del Sindae tiene un papel fundamental en la promoción de incentivos para la participación de los diferentes actores que lo componen. Por lo tanto, es necesario que la AEB coordine los esfuerzos entre las organizaciones para permitir el desempeño adecuado de cada una de ellas y una implementación exitosa del PNAE.

Palabras clave: gobernanza, centro estratégico, sector espacial

The governance of brazilian space sector: AEB in exercise of the Sindae Strategic Center

The main objective of this article was to analyze, focusing on institutionalist theory, the influence of the role of Brazilian Space Agency (AEB) as general coordinator of the National System for the Development of Space Activities (Sindae) in results of implementation of the National Space Activities Program (PNAE), from 1996 to 2018. The research was developed with a case study approach and the combination of different data sources, such as: laws and general rules, academic and technical publications and formal interviews. The main results found point to a concentration of power in research institutes; an inversion of roles between research institutes and companies within the PNAE; and the need to strengthen AEB's role as a strategic center for Sindae. The Sindae strategic governance center has a fundamental role in promoting incentives for the participation of the different actors that compose it. Thus, it is necessary for the AEB to coordinate the efforts between organizations to enable the adequate performance of each of them and a successful implementation of the PNAE.

Keywords: governance, strategic center, space sector 


\section{Introdução}

$\mathrm{O}$ artigo se propõe a analisar a governança de implementação do Programa Nacional de Atividades Espaciais (Pnae) no período de 1996 a 2018, examinando o papel da AEB enquanto coordenadora-geral do Sistema Nacional de Desenvolvimento das Atividades Espaciais (Sindae). Ao longo deste trabalho, falar-se-á do funcionamento do Sindae como instância formal responsável por organizar a execução das atividades espaciais.

Os programas espaciais são muito valorizados mundo afora, pois os poucos países $^{1}$ que conseguem acessar o espaço são dotados de status e poder. Além disso, dominar as tecnologias de desenvolvimento de satélites e lançadores é fundamental para fortalecer a autonomia do país e para promover desenvolvimentos tecnológico e econômico. Convém destacar que a economia espacial global movimentou só em 2019 o montante de US\$ 366 bilhões (SATELLITE INDUSTRY ASSOCIATION, 2020), sendo que há uma concentração desse mercado em poucas empresas ${ }^{2}$ de determinados países (EUROCONSULT, 2018).

O Brasil é o quinto país mais populoso do mundo, também o quinto em dimensão territorial e está entre as dez maiores economias do mundo (FUNDO MONETÁRIO INTERNACIONAL, 2020). É também um grande consumidor de serviços espaciais, com destaque para as telecomunicações, além de observação da terra, posicionamento, serviços meteorológicos, entre outros. Essas características justificariam um alto investimento na política espacial como forma de viabilizar, por exemplo, a produção direta de parte das imagens e dos dados de satélites, em substituição aos milhões de reais que são gastos anualmente ${ }^{3}$, por diferentes órgãos governamentais e demais organizações, para comprar imagens de satélites estrangeiros.

No entanto, o Pnae não tem sido um programa priorizado pelo Governo Federal. Apesar de compor uma pauta de estratégia nacional, por apresentar aplicações civis e militares, o programa espacial vivencia um quadro de dificuldades orçamentárias e

\footnotetext{
${ }^{1}$ EUA, Rússia, China, Japão, Índia, Ucrânia, Europa (Agência Espacial Europeia - ESA), Israel, Irã, Coréia do Sul, Coréia do Norte.

${ }^{2}$ No ano de 2017, no mundo atuavam aproximadamente 30 empresas integradoras de satélites (acima de 50 $\mathrm{kg}$ ), 10 integradoras de lançadores, 50 operadoras de infraestrutura de solo e 5 mil empresas prestadoras de serviços satelitais.

${ }^{3}$ Segundo a Comissão Nacional de Cartografia (Concar/MPOG), com apenas uma compra conjunta para imagens de satélites, em 2015 foram gastos pela administração pública cerca de R \$ 7 milhões para um ano.
} 
gerenciais ao longo dos anos, além de sofrer com restrições internacionais ${ }^{4}$ (CÂMARA DOS DEPUTADOS, 2009).

O aporte elevado e constante de recursos é condição básica para a obtenção de resultados no setor. Na década de 1960, o Brasil detinha um protagonismo na área, quando era um dos poucos países que investia. Hoje, para citar um exemplo de país LatinoAmericano, a Argentina já investe um volume muito maior de recursos que o Brasil (alcançando o ápice em 2013 de US\$ 1,2 bilhões anuais) e domina tecnologias não alcançadas por nós, como satélites dos tipos geoestacionário e radar.

Em decorrência do baixo investimento e dos resultados insuficientes obtidos até agora, apesar da relevância política, científica e econômica do setor, o Pnae passa por uma série de questionamentos com relação à sua implementação e eficácia. As discussões envolvem relações de causalidade com a estrutura institucional e coordenação política, falta de hierarquia entre os órgãos, baixa dotação orçamentária e ausência de sinergia entre os projetos propostos, além de inadequação dos instrumentos jurídicos e legais necessários à sua execução (SECRETARIA DE Assuntos EstratÉGICOS, 2011; CÂMARA Dos Deputados, 2009).

A literatura acima apresenta um conjunto de causas relacionadas aos resultados insuficientes apresentados pelo Pnae nos últimos anos. O presente trabalho traz uma análise aprofundada de um aspecto considerado central para compreender o cenário em que se encontra o Pnae: a coordenação-geral da AEB como órgão central do arranjo institucional de implementação do Pnae, o Sindae. Assim, em termos de estrutura, este artigo traz, além desta introdução, o referencial teórico dos institucionalistas no item 2. Na sequência, é detalhada a metodologia de pesquisa. $\mathrm{O}$ item 4 apresenta a descrição das variáveis de análise, enquanto o item 5 traz os resultados do arranjo institucional do Pnae, no período de 1996 a 2018. Por fim, este trabalho é composto por uma conclusão, com os achados e recomendações da pesquisa.

\section{Referencial Teórico}

Instituições são, a partir da definição de Douglass North (1998), as regras formais e informais que regulam as interações sociais ou, ainda, são "as regras do jogo numa

\footnotetext{
${ }^{4}$ Os países que têm independência no acesso ao espaço dificultam, com embargos comerciais e políticos, o acesso por outros países a componentes, subsistemas e sistemas que são fundamentais para o desenvolvimento de satélites e lançadores próprios.
} 
sociedade; mais formalmente, representam os limites estabelecidos pelo homem para disciplinar as interações humanas. Consequentemente, e em compensação, estruturam incentivos de natureza política, social e econômica" (NORTH, 1998, p. 7).

Se as instituições constituem a regra do jogo, as organizações são os jogadores. Em outras palavras, são os grupos de indivíduos voltados para determinada atividade, a qual é realizada com um fim específico. São as limitações institucionais impostas que definem o leque de oportunidades e, portanto, os tipos de organizações a serem fundadas.

Por sua vez, o ambiente institucional (institutional environment), segundo Davis e North (1971, p. 6), é formado pelas regras políticas, sociais e legais mais básicas e gerais que definem os fundamentos para o desenvolvimento do sistema econômico. São essas regras básicas e gerais que definem o sistema político e econômico. As regras do ambiente institucional, contudo, transcendem o sistema político e econômico e definem as regras que os agentes privados estabelecem para si em suas transações econômicas ou nas relações políticas e sociais particulares, as quais constituem os arranjos institucionais (DAVIS; NORTH, 1971). Em outras palavras, o arranjo institucional é um conjunto de regras que define a forma pela qual agentes econômicos podem cooperar ou competir (DAVIS; NoRTH, 1971), ou, ainda, as regras que definem a forma de coordenar um conjunto específico de atividades econômicas em uma sociedade (FIANI, 2011, p. 4).

Oliver Williamson (2012) apresenta os diferentes arranjos institucionais (ou estruturas de governança ${ }^{5}$ ) possíveis de organizarem o sistema econômico. A definição desses arranjos, com vistas a garantir a melhor estrutura de governança e com o menor custo de transação possível, leva em conta três aspectos:

(i) a incerteza: diz respeito ao grau de confiança em antecipar ações. Desse modo, para se proteger em cenários incertos, os contratos tendem a ser mais complexos e com mais garantias;

(ii) a frequência das transações: quanto mais frequente, mais complexa tende a ser a relação entre as partes. Exemplo: a compra recorrente de determinados insumos requer contratos mais detalhados e com regras para atrasos e não cumprimentos; e

\footnotetext{
5 Oliver Williamson emprega o termo "estrutura de governança" no mesmo sentido de "arranjo institucional" de Douglass North. Neste trabalho, será empregado o termo "arranjo institucional", apesar do arcabouço teórico de estruturas híbridas e centros estratégicos serem oriundos de Williamson e desenvolvido por Claude Ménard, por exemplo. A escolha do termo a ser utilizado perpassa a ampla variedade de situações em que a palavra governança é empregada, evitando-se, assim, possíveis equívocos.
} 
(iii) as especificidades do ativo: diz respeito ao quanto os ativos são específicos de tais atividades, isto é, em caso de encerramento das atividades em que grau eles poderiam ser reaproveitados. Segundo Fiani (2013, p. 25), “ativos específicos são aqueles que não podem ser aplicados em uma atividade diferente daquela para a qual foram planejados, sem com isso sofrerem uma redução expressiva no seu valor, além daquela que eventualmente decorra da apreciação pelo uso".

Com base nos três aspectos, as relações econômicas podem estar organizadas em forma de: (1) mercado, (2) hierárquicas ou (3) de estruturas híbridas. Esse entendimento é importante quando se deseja estudar as condições institucionais mais adequadas para o desenvolvimento econômico.

A estrutura de mercado é a mais impessoal dos arranjos, pois se sustenta pelo mecanismo de preço. O mercado, através dos processos de compra e venda, é o responsável por determinar as transações. Os agentes irão tentar reduzir seus custos, através da barganha e das economias de escala e de escopo. O mercado é a melhor opção de arranjo quando os ativos não apresentam especificidade significativa, as regras que regem as transações desse ativo são gerais e simples de serem aplicadas indistintamente a qualquer transação. Nesses casos, independente da frequência com que as transações acontecem, o mercado demonstra ser a melhor estrutura de governança.

A estrutura hierárquica apresenta a verticalização da cadeia produtiva, absorvendo os segmentos a jusante ou a montante, como forma de reduzir os custos. Os mecanismos de controle se tornam mais presentes e atuam para garantir a redução de custo de forma integrada. As decisões se dão pela autoridade hierárquica, como acontece na administração de empresas públicas e privadas, na administração pública direta. Nesse ambiente, as relações de interdependência mútuas são muito importantes, por isso, a busca por soluções cooperativas exige forte controle administrativo e poucos incentivos. Essa estrutura é ideal quando os ativos possuem alta especificidade e a frequência das transações também é alta.

Por fim, as estruturas híbridas se encontram entre as estruturas de mercado e as estruturas hierárquicas. Aquelas estão no meio termo exatamente por conterem elementos de incentivos e também de controle, reservando espaço tanto para a adaptação autônoma (como na estrutura de mercado), quanto para a adaptação coordenada (como na estrutura hierárquica). A estrutura híbrida é ideal quando os ativos envolvidos apresentam alguma especificidade e as transações acontecem frequentemente; ou quando os ativos possuem 
alta especificidade (como é o caso de satélites e lançadores), no entanto, há baixa frequência de transações (como no setor espacial, em que há poucos projetos e também um número reduzido de atores). É essa estrutura adequada para compreender o setor espacial, por isso, será considerada na análise.

Claude Ménard (2011) foi um dos principais autores a desenvolver os conceitos elaborados por Williamson. Um desses foi o de centro estratégico ou, nos termos de Ménard, "entidade estratégica". O centro estratégico é responsável pela coordenação das organizações, manipulando os incentivos e controles administrativos de intensidade moderada que caracterizam os híbridos, com o objetivo de preservar a relação entre os agentes, evitando-se, assim, a depreciação dos ativos específicos na forma de recursos compartilhados.

O centro estratégico faz-se necessário, em especial, quando as organizações possuem ativos e direitos compartilhados na relação, assim como o centro estratégico. Nesses casos, embora as organizações possuam recompensas individuais, haverá também aquelas conjuntas cuja relação de alocação entre organizações é definida pelo centro estratégico.

Para Ménard (2011), existe extensa variedade de possibilidade de combinações das três dimensões que compõem um centro estratégico, a saber: os ativos específicos, os direitos de decisão e os pagamentos associados com os direitos de propriedade. A presença ou ausência de uma entidade coordenadora e a extensão de sua autoridade, quando ela existir é o que parece diferenciar os arranjos no amplo espectro das organizações de modelo híbridos.

Ménard (2011) entende que a motivação para os parceiros cederem parte de seus direitos em tomar decisão e optarem por estruturas híbridas, deve-se a três fatores. Primeiro, ao entendimento da complexidade da situação, que se deve à necessidade de coordenar múltiplas transações entrelaçadas ou a um ambiente em processo de mudança. Segundo, as partes podem ver na parceria uma resposta à dependência de recursos, assegurando o acesso a recursos existentes ou facilitando o acesso a novos, em especial quando o tamanho dos investimentos necessários extrapola as capacidades individuais. Por fim, o terceiro fator consiste no entendimento de que o retorno esperado da interação entre as partes pode não ser calculável ex ante.

Assim, os parceiros buscam soluções organizacionais que facilitam negociações ex post para compartilhar ativos com os menores custos de transação possíveis. Para isso, 
são buscados contratos que garantam uma divisão satisfatória dos ganhos. No entanto, a definição dessas regras não é trivial. Além disso, a compreensão analítica que se tem a respeito das regras contratuais que realmente funcionam é limitada.

Por fim, os híbridos geralmente são coordenados através de um corpo formal, o qual funciona como depositário de autoridade competente para monitorar as ações conjuntas. Esse corpo pode ter diferentes formas, como assembleias e conselho, ou uma entidade permanente específica. Quaisquer desses arranjos envolvem a centralização de decisões, um nível não desprezível de regras formais e controle parcial sobre os direitos de propriedade (MENARD, 2011).

Ainda, com o intuito de ampliar a compreensão sobre governança (ou arranjo institucional) ${ }^{6}$, é importante trazer as considerações de Capano, Howlett e Ramesh (2015). Os autores apresentam governança como uma forma de análise da complexidade contemporânea do processo de fazer política pública. Eles consideram o conceito importante para redefinir o escopo de pesquisa de políticas públicas, em que muitos atores interagem de maneira formal e informal.

Os autores detalham três aspectos do conceito de governança, a saber: dinâmica, estratégia e capacidade. O primeiro trata da característica de instabilidade da governança. Esta não é estável, muda e se ajusta ao tempo, às mudanças de arquitetura institucional e às ferramentas de políticas públicas. Nessa perspectiva, um modo de governança é um equilíbrio do momento e não uma construção estável e permanente. Dessa forma, este estudo terá como recorte o arranjo institucional vigente, ciente de que ele representa uma foto apenas.

A estratégia de governança reflete a habilidade dos governos em alterar os arranjos de governança e dar a eles sua característica dinâmica. Por trás de cada equilíbrio de governança existe a intenção de diferentes atores em criar arranjos favoráveis para atingir seus propósitos específicos e tornar aqueles o mais estáveis possível.

Já a capacidade de governança enfatiza que nem todo mecanismo de governança é igualmente bem-sucedido em gerar os resultados governamentais esperados. Para os autores, um arranjo de governança é efetivo quando capaz de resolver problemas políticos e de políticas públicas, no entanto, apenas o desenho e a busca de consolidação de um arranjo específico não garantem que ele será bem-sucedido.

\footnotetext{
${ }^{6}$ Existe toda uma literatura que trata das especificidades desses dois termos, aproximando-os ou afastando-os. Aqui, com base na literatura elencada, estamos considerando sinônimos.
} 


\section{Metodologia de Pesquisa}

A abordagem selecionada para a pesquisa foi o estudo de caso. Segundo Yin (2001), essa é a melhor estratégia de pesquisa para os casos em que se quer analisar os acontecimentos contemporâneos, complexos e dinâmicos, sem condições de manipular comportamentos relevantes e sendo as condições contextuais não discerníveis do fenômeno de estudo, como é o caso da temática apresentada acima.

Foi realizado um estudo de caso único, baseado no fundamento lógico de ser um caso revelador, como é o caso de uma análise do arranjo institucional do setor espacial. Foram utilizadas diferentes fontes de evidência, para que houvesse uma triangulação entre elas. Além disso, o embasamento teórico subsidiou a elaboração de proposições prévias que nortearam a coleta e a análise dos dados. Os dados analisados foram encontrados em: (i) leis e normas gerais, (ii) publicações acadêmicas e técnicas e (iii) entrevistas formais.

A escolha dos entrevistados seguiu a estratégia de seleção não randômica sampling for range - com a identificação de subcategorias do grupo em análise, no caso, organizações públicas e privadas que interagem no âmbito do arranjo da política espacial (WeISS, 1994 apud SMALl, 2009). Nesse sentido, foram realizadas entrevistas com representantes da AEB; do Instituto Nacional de Pesquisas Espaciais (Inpe); do Instituto de Aeronáutica e Espaço (IAE). Também foi entrevistado representante do Parque Tecnológico São José dos Campos, onde há presença de empresas do setor espacial e um ambiente propício para a geração de inovação. Ainda foram entrevistados representantes de empresas do setor espacial, atentando-se para a diversidade dos segmentos de satélites e de lançadores. Assim, foram totalizadas sete entrevistas, com representatividade qualitativa de organizações e com atores de nível estratégico, considerando o tamanho do setor no Brasil. Também por esse motivo, a identidade dos entrevistados tem caráter sigiloso.

Todos esses parâmetros metodológicos buscaram encontrar evidências para responder à seguinte pergunta de pesquisa: como a coordenação-geral da AEB no Sindae influenciou os resultados de implementação do Pnae de 1996 a 2018? Tem-se como variável dependente os resultados do Pnae nesse período e, como variável independente, a coordenação-geral da AEB no Sindae. A hipótese é que a coordenação-geral da AEB se apresentou fragilizada no período de análise, ficando o sistema carente de uma 
coordenação efetiva dos esforços e recursos das instituições-membro do arranjo, assim, influenciando diretamente nos resultados insuficientes do programa.

\section{Estudo de caso: descrição das variáveis de análise}

\subsection{A Lei de criação da AEB e o Sindae}

A Lei $\mathrm{n}^{\circ}$ 8.854/1994 criou, com natureza civil, a AEB, autarquia federal vinculada à Presidência da República, com a finalidade de promover o desenvolvimento das atividades espaciais de interesse nacional. No entanto, após a edição e reedição de diversas medidas provisórias que permitiram a formalização do Decreto $n^{\circ} 3.566 / 2000$, a AEB passou a estar vinculada ao Ministério da Ciência e Tecnologia e não mais à Presidência da República.

A AEB foi criada devido à importância internacional de se ter uma agência civil na coordenação do programa espacial. A gestão civil permite realizar parcerias internacionais e reforçar o uso pacífico do espaço exterior pelo Brasil. A questão de coordenação civil é tão importante que a tentativa de aquisição de sistemas espaciais idênticos, quando realizada por uma instituição civil brasileira, é realizada com mais sucesso do que a mesma tentativa por uma instituição militar brasileira, que sofre embargos (é o caso de componentes e subsistemas para o desenvolvimento da Plataforma Suborbital de Microgravidade - PSM).

Entre as competências da AEB (BRASIL, 1994, art. $3^{\circ}$ ) estão a geração de tecnologias e inovação com a participação do setor privado e a integração entre este e as entidades envolvidas nas pesquisas espaciais, que, em geral, são os institutos de pesquisa e universidades.

$\mathrm{O}$ art. $4^{\circ}$ da Lei $\mathrm{n}^{\circ}$ 8.854/94 define que as atividades espaciais brasileiras serão organizadas sob forma sistêmica, sendo a AEB o órgão central desse sistema. $\mathrm{O}$ art. $5^{\circ}$ define a estrutura básica de composição da AEB e cria, além da presidência, da diretoriageral e dos departamentos, o Conselho Superior da AEB. Este é um órgão colegiado, de caráter deliberativo, formado por representantes da AEB, de ministérios e secretarias da Presidência, da comunidade científica e do setor industrial.

Cabe destacar que a estrutura da AEB foi alterada posteriormente por outros instrumentos infralegais, sendo que a última alteração ocorreu por meio do Decreto $\mathrm{n}^{\circ}$ 10.469, de 19 de agosto de 2020. Desde sua constituição, a AEB é composta, 
principalmente, pela Presidência, pelo Conselho Superior e por Diretorias. Os dois primeiros são classificados como órgão de deliberação superior. E, apesar da previsão em lei e da ratificação em todas as estruturas regimentais subsequentes, o Conselho Superior da AEB não se reúne com regularidade (a última reunião aconteceu em 2015) e tampouco desempenha os papéis de deliberação que lhe competem, tais como sobre as atualizações da Política Nacional de Desenvolvimento das Atividades Espaciais (Pndae) e do Pnae, sobre organização e funcionamento do Sindae, entre outros.

Já o Decreto no 1953/1996, instituiu o Sindae com a finalidade de organizar a execução das atividades destinadas ao desenvolvimento espacial de interesse nacional. $\mathrm{O}$ Sindae é constituído por um (i) órgão central, a AEB, responsável por sua coordenaçãogeral; (ii) por órgãos setoriais, responsáveis pela coordenação setorial e execução das ações contidas no Pnae, o DCTA e o Inpe; e (iii) por órgãos e entidades participantes, responsáveis pela execução de ações específicas do Pnae, como ministérios e secretarias da Presidência; Estados, Distrito Federal e municípios; e setor privado.

O decreto define, ainda, que cabe ao Conselho Superior da AEB a aprovação do ingresso no Sindae no caso do item "iii”" acima; assim como elaborar resolução normativa sobre o seu funcionamento. Cabe destacar que essa resolução não foi elaborada, de forma que, na prática, o Sindae não tem sua forma de atuação definida. Não foram estruturados grupos de discussões, com reuniões periódicas, e, tampouco, a execução das atividades espaciais são definidas de maneira sistêmica e com a participação de todos os membros do sistema.

A praxe tem sido uma atuação fragmentada dos atores, em que a AEB tem relação perene e contínua, porém, separada com o Inpe, para os temas relacionados a satélites, educação e aplicações espaciais; e com o DCTA, quando a temática se refere a lançadores, centros de lançamento, atividades espaciais de uso dual (civil e militar). Cabe destacar que dentro da estrutura do DCTA está o IAE, para o qual a AEB destina recursos para pesquisas e desenvolvimento de lançadores e de propulsores.

Um ponto importante a ser considerado é que, apesar de haver essa relação estabelecida entre a AEB e essas instituições setoriais, a relação, historicamente, não tem sido de coordenação por parte da AEB. Em decorrência de inúmeros fatores que serão tratados em seguida, as relações ficaram concentradas em torno do repasse de recursos pela AEB, que acabou por exercer mais a função de fiscalizadora das transferências, já 
que havia historicamente bastante autonomia dos institutos de pesquisa em definirem os requisitos estratégicos das missões espaciais a serem desenvolvidas.

\subsection{A PNDAE e o Pnae}

Em 1994, também foi publicado o Decreto $n^{\circ} 1.332$, que aprova a atualização da PNDAE. Já nas considerações iniciais do texto, reconhece que os avanços do Brasil no setor espacial precisam ser consolidados e ampliados, com participação tanto do setor governamental quanto do privado e, em especial, do parque industrial brasileiro.

A PNDAE tem como objetivo geral "promover a capacidade do país para, segundo conveniência e critérios próprios, utilizar os recursos e as técnicas espaciais na solução de problemas nacionais e em benefício da sociedade brasileira" (BRASIL, 1994a, item IV do Anexo I). A partir desse objetivo geral, foram definidos os objetivos específicos ${ }^{7}$.

A materialização das diretrizes da PNDAE é realizada através do Pnae. Este consiste no planejamento programático das atividades espaciais, em geral, para um período decenal. As versões do Pnae expressam um programa com atividades e metas bem definidas, e com absoluta clareza textual sobre a importância de integrar atores no processo de fortalecimento do país como uma referência no setor espacial. Por outro lado, o Pnae apresenta um volume de projetos desconexos que competem entre si, além de dificuldade na implementação, em função de diversos problemas de ordem administrativa, política, financeira, legal e de pessoal (CÂMARA DOS DEPUTADOS, 2009). Em termos de realização de atividades e alcance de metas, o resultado, ao longo dos anos, tem sido o atraso no cumprimento das atividades e dos cronogramas estabelecidos.

No que se refere às versões do Pnae, a primeira (1996 a 2005), de cunho mais programático, é abrangente, ambiciosa e apresenta todas as necessidades do setor, de forma descolada da realidade orçamentária das instituições componentes do Sindae. A versão de 1998 a 2007 apresenta apenas uma atualização da anterior em termos de compromissos programáticos de um novo mandato político. Em termos de resultados, a segunda versão do Pnae está temporalmente próxima da primeira e colhe os resultados já previstos nesta, sendo ligeiramente significativos os resultados relacionados aos programas dos satélites SCD e CBERS. A terceira versão (2005 a 2014) traz prioridades para o período decenal e muitas delas são estratégias de implementação. Das entregas

\footnotetext{
7 Para detalhes, consultar o Item IV do Anexo 1 do Decreto n ${ }^{\circ} 1.332$, de 8 de dezembro de 1994a.
} 
previstas, boa parte se concentra na continuação de projetos anteriores, tendo se concretizado, no que diz respeito a satélites e lançadores, apenas as ações relativas ao projeto CBERS.

Em relação aos resultados do último Pnae (2012 - 2021), dos doze satélites previstos para serem entregues no decênio, apenas três foram lançados (CBERS-3, em 2013 e CBERS-4, em 2014, ambos sem atrasos; e SGDC-1, em 2017, com três anos de atraso) e há previsão de lançamento de um quarto satélite, o Amazônia-1, agora em 2020. O desenvolvimento tecnológico brasileiro ficou restrito aos satélites de observação da terra, sendo que não dominamos ainda tecnologias de satélite radar, fundamentais para monitoramento da Amazônia, por exemplo; nem satélites de telecomunicações, como o Satélite Geoestacionário de Defesa e Comunicações (SGDC), que foi comprado da França.

No segmento de lançadores, dos cinco artefatos (VLM, VLS-1, VLS-Alfa, VLSBeta, Cyclone-4) previstos para estarem prontos entre 2013 e 2020, nenhum deles foi desenvolvido ainda. Apenas o desenvolvimento do VLM tem sido realizado, em parceria com a Alemanha, mas conta com cerca de cinco anos de atraso. O Brasil ainda não possui um lançador próprio de satélite, o que nos exclui, por ora, da lista de países que têm autonomia no acesso ao espaço.

\section{Resultados: a análise do arranjo de implementação do Pnae no período de 1996 $-2018$}

As legislações criam um ambiente institucional macro, o qual define as linhas gerais de atuação e possibilidades jurídicas e estratégicas a serem seguidas. Na prática, as decisões tomadas ao longo do tempo e as ações realizadas concretizaram um arranjo institucional idiossincrático para o setor espacial, com características adquiridas a partir (i) da interação recorrente entre os atores públicos e privados envolvidos; e (ii) das regras, que definem a forma pela qual os agentes econômicos podem cooperar ou competir (DAVIS; NORTH, 1971).

Esse arranjo institucional é considerado híbrido, segundo a literatura, porque o setor é estratégico, mobiliza recursos variados de grande natureza, combina ativos muito 
específicos, porém com baixa frequência de transações ${ }^{8}$. Além disso, tal arranjo fundamenta-se na necessidade de coordenação de atores públicos e privados, com incentivos e controles variados, para que esses cooperem e trabalhem com vistas à consecução de determinados objetivos econômicos e tecnológicos. Para a coordenação dos arranjos híbridos, o ideal é que sejam usados elementos de incentivos e também de controle, reservando espaço tanto para a adaptação autônoma - comum aos arranjos de mercado -, quanto para a adaptação coordenada - usada nos arranjos hierárquicos.

\subsection{A coordenação-geral do Sindae}

A AEB tem a competência legal de atuar como coordenadora-geral do Sindae. A Agência acumula funções de planejamento, execução, coordenação e controle, no entanto, apesar de ter sido criada em 1994, o primeiro concurso público para lotação de servidores foi realizado somente em 2014, com nomeação e posse de 64 servidores em julho de 2016. Dessa forma, a instituição passou 22 anos com um quadro restrito de pessoal, contando com servidores cedidos de outros órgãos, comissionados e terceirizados ${ }^{9}$. Grande parte desses profissionais recebia uma remuneração incompatível com o grau de responsabilidade exercido.

A ausência do concurso também contribuiu para a concentração de engenheiros e físicos no quadro da instituição, que acabou por carecer, por muitos anos, de um quadro de pessoal multidisciplinar, com capacidades e habilidades de negociação em áreas como políticas públicas, administração, economia, entre outros.

As circunstâncias acima acarretaram carência de força política da AEB para (i) liderar ou interferir nas decisões do programa espacial, (ii) para dar visibilidade à Política Espacial e à própria Agência e (iii) para negociar com os altos escalões dos governos a priorização do tema e a destinação de recursos financeiros e humanos.

A AEB, por muito tempo, ficou restrita à função de ordenadora de despesas para dois grandes executores do Pnae: o DCTA, na área de lançadores, e o Inpe, na área de satélites e aplicações. Em alguns casos, sendo deixada à parte de decisões estratégicas.

\footnotetext{
${ }^{8}$ Quanto à baixa frequência das transações no setor espacial, esta é reflexo da quantidade de projetos realizados no setor. Em decorrência especialmente do baixo orçamento público dos últimos anos, o número de projetos executados no Pnae foi muito baixo. "Estou aqui no setor há uns seis anos talvez, não houve projeto novo nesse período" (Entrevista 6).

${ }^{9}$ Apenas dez servidores de órgãos extintos foram distribuídos para AEB em 1999. Esses se aposentaram ao longo do tempo e hoje restam apenas seis ativos.
} 
Os institutos detêm: (i) forte capital político (o DCTA está ligado ao Ministério da Defesa, o Inpe, ao MCTIC); (ii) capital tecnológico (os dois dominam tecnologicamente as suas respectivas áreas e têm interesses próprios de pesquisa, o que muitas vezes influenciou na decisão de qual satélite ou lançador deveria ser construído, a despeito do retorno para a sociedade); e (iii) corpo técnico, pois o DCTA detém cerca de 1.500 colaboradores, o INPE próximo de 780, enquanto que a AEB detém cerca de 140, de acordo com o Portal da Transparência.

\begin{abstract}
"Por dever de ofício, a relação da AEB com os institutos começou muito cedo, logo depois de ser criada. Mas, por dever de competência, só foi adquirida há pouco tempo, depois que conseguimos trazer gente tecnicamente capaz para a Agência. Fomos um grupo de pessoas que, em sua maioria, não éramos habilitados para discutir, em um nível mais técnico, as atitudes que cada instituto gostaria de tomar. Havia discussões sobre a parte orçamentária, mas não conseguíamos vencer por argumentos técnicos. Há alguns anos atrás conseguimos começar a dar direcionamento técnico para as questões, é claro que isso gera desconforto para os nossos institutos, mas que acaba sendo reconhecido (...) tanto que o Inpe queria levar pessoal da AEB para trabalhar lá" (Entrevista 2).
\end{abstract}

Os institutos desempenham atribuições diversas, além da atividade espacial (Entrevista 7). O Inpe, além da engenharia espacial e do LIT, trabalha com astrofísica, meteorologia, entre outras, as quais, apesar de usarem serviços espaciais, compõem leques diferentes de atividades. Da mesma maneira, o DCTA é responsável não só pelo IAE, mas por diversas instituições de ensino e pesquisa militares e/ou vinculadas às Forças Armadas, como o Instituto Tecnológico de Aeronáutica (ITA) e a Academia da Força Aérea (AFA). A AEB, ao contrário, foi criada exclusivamente para tratar da temática espacial.

A desconstrução da AEB como mera repassadora de recursos não é trivial, devido às relações de poder já consolidadas no sistema. Um colaborador da indústria traz um exemplo relacionado a empresas integradoras ${ }^{10}$ : “AEB é uma forte entusiasta da ideia de integradora, mas ela tem dificuldade de fazer essa visão desdobrar" (Entrevista 6). Há, naturalmente, resistência dos institutos em alterar tal situação (os motivos serão explicitados em seguida), como forma de preservar os poderes adquiridos e de manter a prevalência de seus interesses.

\footnotetext{
${ }^{10}$ A integração de sistemas refere-se a atividades de integrar componentes, habilidades e conhecimentos de outras organizações, para produzir sistemas cada vez mais complexos. "Quanto mais complexa, de alta tecnologia e de alto custo for a integração de sistemas, mais significativa ela será para a atividade da empresa e do conjunto do setor" (FERREIRA, 2016. p. 4). São as integradoras finais, produtoras de satélites e lançadores, que comandam o conjunto da cadeia produtiva e que também respondem pela maior parcela de valor agregado.
} 
No que tange à visibilidade do Pnae, as aplicações espaciais são fundamentais para setores como defesa, comunicações e meteorologia, bem como para tarefas de observação e posicionamento da Terra. Apesar disso, no Brasil, os produtos das atividades espaciais não são amplamente reconhecidos como tal, de forma que se perde a oportunidade de mobilizar diversos setores econômicos e sociais para pressionarem, conjuntamente com a AEB, pela priorização política e orçamentária do Pnae.

Outra fragilidade relacionada às aplicações espaciais é quando há interesse dos órgãos governamentais (e também de empresas privadas sediadas no país) em adquirirem e operarem um satélite: as instituições não o adquirem de empresas brasileiras, como foi o caso do SGDC. A falta de preparo das empresas brasileiras em realizarem esse fornecimento é usada como justificativa (Entrevista 7). Por outro lado, essas empresas só serão competentes para realizar tais fornecimentos se forem contratadas pelo Estado, se este usar o seu poder de compras, com encomendas frequentes, para desenvolver a indústria, assim como é feito em outros países. Setores intensivos em tecnologia necessitam de investimentos recorrentes e sem cortes, para garantirem o processo de inovação, o qual é fruto de processos rotineiros.

Relativo ao orçamento, o Pnae sempre contou com recursos do orçamento da União como sua principal fonte de financiamento. Desde a criação da AEB, em 1994, os recursos são geridos pela Agência, porém sofrem grandes variações ao longo dos anos e, a despeito da programação decenal do Pnae, os recursos programados para sua execução não chegam em sua totalidade. "Ninguém faz Programa Espacial com 200 milhões por ano, o próprio PNAE previa investimento de um bilhão por ano e não está acontecendo" (Entrevista 1).

Em 2000, houve tentativa de alavancar o volume de recursos investidos, buscando diversificar suas fontes de financiamento com a criação do Fundo Espacial/FNDCT, adotando-se outras fontes de receita. No entanto, essas fontes revelaram-se absolutamente inócuas, contingenciáveis e não foram suficientes para o propósito da sua criação (S AE, 2009; AEB, 2018a).

O Gráfico 1 a seguir demonstra o limite orçamentário da AEB nos últimos dez anos, além de comparar a dotação orçamentária com aquilo que foi realmente empenhado no âmbito dos programas da AEB. Inicialmente designado Programa Nacional de Atividades Espaciais - 0464, em 2012, passou a ter duas nomenclaturas: Programa Política Espacial - 2056 e Programa de Gestão - 2106. O Gráfico 1 inclui, portanto, ações 
de gestão e da área finalística ${ }^{11}$. É possível perceber que, em dez anos, houve queda dos recursos empenhados de $\mathrm{R} \$ 289$ milhões, em 2009, para $\mathrm{R} \$ 164$ milhões em 2018.

${ }^{11}$ Foram excluídas as Despesas de Grupo 1 e a Ação Orçamentária vinculada à Alcântara Cyclone Space. 


\section{Gráfico 1 - Limite orçamentário da AEB - 2009 a 2018}

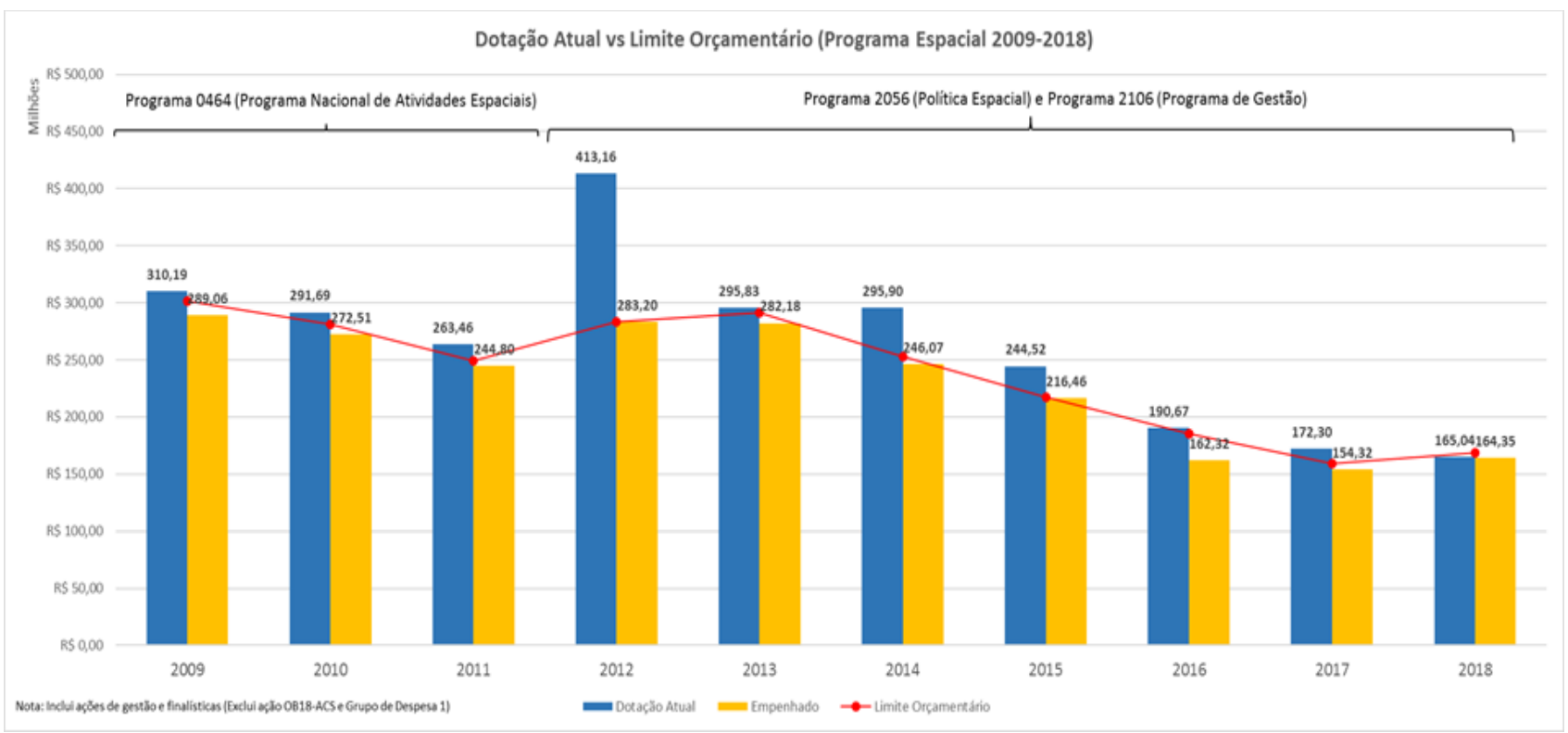

Fonte: AEB, 2018b.

Como consequência da mencionada carência de força política da AEB, observase a queda no volume de recursos no Gráfico acima, o que provoca grande impacto no setor como um todo e, em especial, na indústria espacial. De acordo com o estudo da SAE de 2009:

a construção de satélites, de foguetes e de infraestrutura terrestre apresenta complexidade e riscos tecnológicos, alto custo e ciclos de desenvolvimento longos, em geral entre quatro e oito anos. Dessa forma, a gestão dos projetos e das atividades espaciais torna-se refém da incerteza, em longo prazo, do suporte financeiro necessário à execução das tarefas e dos contratos envolvidos, o que acaba gerando constantes soluções de continuidade e ações desgastantes e contínuas de replanejamento. Ademais, períodos de penúria de recursos traduzem-se em atrasos sucessivos de cronograma com consequente obsolescência da infraestrutura, atraso tecnológico, dissolução de parcerias internacionais e dispersão ou perda de pessoal. Entre os principais prejudicados com tal situação, encontra-se o setor industrial nacional, formado por pequenas e médias empresas incapazes de suportar atrasos em pagamentos contratuais ou a falta de contratos por longo tempo (SAE, 2009, p. 24).

Um agravante do baixo volume de recursos é a pulverização de gastos em projetos dispersos e não articulados entre si (Entrevistas 3 e 7). "Os isolamentos das instituições governamentais que compõem o Sindae permanecem. De longa data, não existem coordenação e compatibilidade de metas e objetivos entre o desenvolvimento de veículos lançadores e o desenvolvimento de satélites" (VAZ, 2009, p. 226). A tarefa de coordenação deveria ser desempenhada pela AEB, porém, esta apresenta dificuldades em fazê-la. Assim, não são gerados resultados positivos para o setor espacial e, tampouco, os 
atores políticos não são sensibilizados sobre a importância de destinação de uma parcela significativa do montante de recursos orçamentários da União para o Pnae.

Cabe ressaltar que a AEB é uma autarquia comum e, ao contrário de outras agências públicas, como a Agência Nacional de Telecomunicações (Anatel) e a Agência Nacional de Energia Elétrica (Aneel), não possui poder de regulação ou de sanção sobre os executores da política. Tampouco dispõe do mesmo grau de autonomia administrativa que as agências reguladoras, por não ser uma autarquia especial (CÂMARA DOS DEPUTADOS, 2009).

Concebida para sinalizar aos parceiros internacionais que o programa brasileiro estaria sob comando civil, a AEB “conferiu maior complexidade à organização política do programa, mas não instituiu uma hierarquia na definição de tarefas, o que suscitou problemas de coordenação e articulação entre os projetos e disputa em torno dos recursos orçamentários" (CÂMARA DOS DEPUTADOS, 2009, p. 53).

Com equipe reduzida, insuficiência de capacidade estatal (tanto políticorelacional, quanto técnico-burocrática), quadro orçamentário enxuto e sem apoio da sociedade, a AEB apresenta dificuldade em exercer as atividades de coordenação-geral do complexo arranjo que implementa o Pnae (CÂMARA DOS DePUTADOS, 2009; Entrevistas).

Diante da realidade em que se apresenta, em que falta o exercício de coordenaçãogeral em diferentes aspectos, sugere-se, à luz da literatura (MÉNARD, 2011), que a AEB ocupe o papel de centro estratégico, como responsável pela coordenação das organizações envolvidas no sistema e pelo equilíbrio entre os incentivos e controles administrativos e políticos típicos de arranjo híbrido. Para isso, percebe-se a necessidade de internalização de capacidades estatais no âmbito da AEB que favorecessem essa possibilidade.

\section{2. Órgãos setoriais do Sindae}

O Decreto $n^{\circ} 1.953 / 1996$, que instituiu o Sindae, definiu como órgãos setoriais o Inpe e o DCTA, responsáveis pela coordenação setorial e execução das ações contidas no Pnae. Historicamente, ficaram conhecidos como os "executores" do Pnae, detendo muita autonomia para tomar decisões estratégicas e nortear a atuação do programa, de forma desarticulada entre si e também com a AEB, que apresenta fragilidades para exercer o seu 
papel de coordenadora-geral. Assim, a atuação dos executores está mais relacionada aos interesses institucionais de cada uma delas do que aos do programa.

A AEB, mesmo sendo detentora dos recursos e, no limite, "dona" dos produtos encomendados, não consegue exercer a contento seu poder de órgão central. A maior concentração de poder dos órgãos setoriais em relação à AEB explica-se por diversos fatores técnicos, entre eles, deterem maior número de funcionários, estrutura mais robusta (incluindo laboratórios de teste) e o conhecimento técnico a respeito dos desenvolvimentos tecnológicos do setor. Porém, a predominância de poder de decisão pelos órgãos setoriais deveu-se, também, a fatores políticos que envolvem a falta de hierarquia entre a AEB e eles, o baixo capital político da AEB para exercer coordenação entre órgãos com capacidades técnicas tão distintas, sendo a AEB o mais enxuto deles.

Nesse contexto, a coordenação de ações entre os dois institutos tecnológicos, Inpe e IAE, ficou comprometida ao longo do tempo. Carvalho (2009, p. 21 e 22) relata a sucessão de acontecimentos tecnológicos, orçamentários e de embargos que inviabilizaram a realização concatenada entre os projetos brasileiros de satélites e de lançadores. Os principais deles foram os sucessivos fracassos do Veículo Lançador de Satélites (VLS), em 1997, 1998 e 2003. Desde então, decidiu-se abandonar o projeto de se ter um lançador robusto e optou-se por desenvolver um lançador de micro e pequenos satélites, o Veículo Lançador de Microssatélites (VLM), cujo desenvolvimento ainda não foi finalizado. Também não houve, desde o princípio, a devida articulação com o Inpe para o desenvolvimento do satélite a ser lançado no VLM. Aqui fica demonstrada a ausência de uma ação de coordenação que articule e convirja os interesses e atuação das organizações envolvidas.

As dificuldades enfrentadas pelo Pnae justificam ainda mais a necessidade de uma coordenação-geral que induza a sinergia entre os dois principais institutos envolvidos, pois as distâncias programáticas e filosóficas entre eles são significativas. Enquanto o IAE prioriza, atualmente, o VLM, visando ao mercado de microssatélites, o Inpe investe na parceria sino-brasileira para a construção dos satélites de sensoriamento remoto da série CBERS, que são lançados da China, e no Amazônia-1.

Apesar de demonstrarem mais força e estrutura do que a AEB, os institutos, ao longo dos anos, vêm tornando-se carentes de recursos orçamentários, de infraestrutura e de pessoal. Segundo a Entrevista 4, eles são "achatados" em termos de recursos necessários para os projetos que o próprio Pnae prevê. Apesar de haver uma expectativa 
de desembolso financeiro, o planejamento nunca é executado. Isso gera grandes atrasos nos projetos e frustra os stakeholders, que não veem resultado e, portanto, não destinam novos recursos à atividade. Acaba que a indústria é também prejudicada por isso, pois "embora sejamos as Autoridades de Projeto de cada subsistema, grande parte das atividades é executada na indústria, porém com essa redução de recursos e projetos acabamos sufocando a indústria. Ela acaba não tendo um fluxo de caixa necessário para se manter funcionando, é um ciclo vicioso" (Entrevista 4).

O corpo técnico está aposentando exponencialmente. Em 12 anos, houve redução de $30 \%$ dos colaboradores e a previsão é de diminuir, em quatro anos, a menos da metade do que se tem hoje. Nesse contexto, os institutos já perderam muita capacidade técnica e conhecimento, pois não foi feita gestão adequada destes, com o repasse a outros pesquisadores da casa, à indústria, às universidades. Devido ao estado preocupante em que os institutos estão, muitas pessoas aposentadas voltaram a ocupar cargos temporários e precários, podendo, a qualquer momento, serem desvinculadas da instituição.

\footnotetext{
"Se formos no INPE e no DCTA iremos ver a precariedade que tem de recursos humanos (...) Os institutos precisam focar nas responsabilidades que eles têm como órgão de governo" (Entrevista 2).

\begin{abstract}
"Atualmente a disponibilidade de recursos humanos que temos não é mais como tinha ano passado, (...) reduzindo isso os desafios ficam maiores, pois tecnologias que dominávamos podem sofrer riscos de serem perdidas. Não adianta deixar um relatório bem feito que é possível de replicar. Na verdade, parte do conhecimento está na cabeça do pesquisador e ele devia ter passado isso para alguém, mas ele foi embora sem passar. Temos um problema de redução do capital intelectual" (Entrevista 4).
\end{abstract}

Essa situação de redução do conhecimento é grave para o setor, pois, ao perder assimilação e aprendizado, regride-se sem avançar no alcance de novas tecnologias e de inovações, tampouco, da fronteira tecnológica. Além disso, a formação de mão de obra leva tempo e, portanto, a reposição não é célere.

\subsection{O setor privado no Sindae}

O Decreto no $1.953 / 1996^{12}$, que instituiu o Sindae, definiu também a participação do setor privado, por indicação de seu representante legal. As relações do setor privado

\footnotetext{
${ }^{12}$ Esse decreto definiu, ainda, a participação de órgãos e entidades responsáveis pela execução de ações específicas do Pnae, como ministérios e secretarias da Presidência; Estados, Distrito Federal e municípios. A relação da AEB com estes acontece de forma esporádica e pontual, não cabendo neste trabalho um detalhamento de tal relação.
} 
no âmbito do Sindae acontecem tanto de forma direta com a AEB, (institucionalmente e de forma contratual, como nos casos em que a AEB contrata diretamente); e também, mais recorrentemente, via institutos de pesquisa.

Segundo a Entrevista 7, dos integrantes do Sindae, a indústria "é uma das que mais sofre. Se o governo faz ou não seu trabalho, os órgãos governamentais existem, a indústria não. Ela acaba se não tiver um contrato, se não tiver fomento, se não tiver ninguém fazendo nada para criar e para manter uma indústria e uma competência industrial". A percepção, em geral, é de que:

\begin{abstract}
“a participação [da indústria no PNAE] foi bastante pequena (...) Os resultados que foram obtidos nos últimos anos mostram como a indústria ficou afastada, por diferentes razões; não é culpa nossa, é culpa da legislação que dificulta a contratação de empresas, dificulta fazer encomendas para as empresas, dificulta o investimento nas ICTs por falta de recurso, que também atrapalha toda contratação. Simplesmente receber as encomendas de uma ICT para desenvolver um determinado componente é um papel coadjuvante, quando comparado com outros países" (Entrevista 8).
\end{abstract}

\title{
5.4. A interação entre empresas e ICTs do setor espacial
}

A interação entre ICTs e empresas do setor espacial é considerada intensa, apesar de não ser regular. A despeito da intensidade, ela é restrita ao desenvolvimento e fabricação de subsistemas, conforme demonstram os grifos abaixo.

\footnotetext{
"Esse projeto é um projeto da ICT para ser industrializado pela empresa, que, ao industrializar, revisita o projeto e faz algumas adaptações durante a fase de industrialização. E durante esse contrato de longo prazo, em que eles vão entregando diversas etapas do contrato, temos um relacionamento muito intenso com a empresa. Dentro dela temos uma comissão técnica que acompanha todos os entregáveis e todas as fases do desenvolvimento desse projeto (...). É uma relação de ganha-ganha, pois acabamos tendo um produto específico de acordo com os requisitos técnicos. Nós não somos responsáveis por industrializar e, do ponto de vista de engenharia, o projeto parece ser realizável. Mas, no final das contas, temos indústrias para saber se é realizável ou não, isso traz um aprendizado em nível de projeto e para a empresa também" (Entrevista 4).
}

"Houve grande participação [de empresas nos projetos desenvolvidos pela ICT]. Por exemplo, estamos agora terminando dois satélites, praticamente todas as partes desse satélite são fabricadas pela indústria nacional (...). Em alguns casos, houve participação da empresa no desenvolvimento do projeto, pois era tecnologia nova. Ao ponto da ICT emprestar equipamentos para empresas poderem desenvolver em seus próprios laboratórios" (Entrevista 3).

Por um lado, esse tipo de interação fez com que a indústria espacial se estabelecesse no Brasil, principalmente aquelas do segmento de satélite. A partir das demandas dos institutos, criou-se uma capacidade industrial instalada, resultando em 
adensamento tecnológico do setor espacial. Tal tipo de interação fez também com que, além das novas empresas criadas, as de outros setores produtivos, fornecedoras em especial para os segmentos de lançadores, se tornassem "inovadoras e competitivas" (Entrevista 4).

Por outro ângulo, a manutenção do tipo de interação estabelecida entre ICTs e empresas até hoje, sem uma transição real e planejada, limita demasiadamente a atuação destas, na medida em que não são dadas oportunidades de participarem das fases de definição $(0, \mathrm{~A})$ do projeto, tampouco de exercerem o papel de integradoras de missões espaciais públicas.

\begin{abstract}
"O projeto nasce dentro das ICTs e são feitas as encomendas, mas sem aplicação de fato (...) Na PMM, o Inpe não estava contratando um satélite, estava contratando uma plataforma, a aplicação daquilo é toda da ICT, sem nenhuma possibilidade de envolvimento da indústria. Da mesma forma o exemplo do motor. Acabam vedando a participação da indústria, e se a indústria estivesse desde a concepção de um projeto, acho que facilitaria bastante a especialização em produtos”. (Entrevista 8)
\end{abstract}

A participação intensa das ICTs no desenvolvimento tecnológico é comum mundialmente no setor espacial, devido aos altos custos e aos grandes desafios enfrentados. No entanto, a tendência é de transferência de tecnologias desenvolvidas pelas ICTs às empresas para comercialização e produção em escala, e não a produção permanente dentro dos institutos, tal como é feito no Brasil, como é o caso do VSB-30 ${ }^{13}$ e, em alguma medida, do CBERS ${ }^{14}$.

Enquanto no arranjo industrial disseminado pelo mundo a indústria participa no mínimo desde a Fase A do projeto, quando há o estudo de viabilidade da missão como um todo, no Brasil, as empresas seguem participando apenas da definição dos subsistemas, isto é, a partir das Fases B (quando participam da definição preliminar) ou C (quando apenas fabricam o produto a partir das especificações já pré-definidas) (Entrevistas 3 e 4). Não houve planejamento e iniciação da transição de competências e

\footnotetext{
${ }^{13}$ Foguete de sondagem direcionado a realizar experimentos em ambientes microgravitacionais. Foi desenvolvido pelo IAE juntamente com a Agência Espacial Alemã (DLR) e teve voo qualificado em 2004. O contrato de transferência tecnológica para indústria nacional foi assinado em 2020, depois de o IAE realizar, por 16 anos, a produção e a integração dos subsistemas que lhe cabem para 27 veículos fornecidos diretamente para Europa, principalmente.

${ }^{14}$ O Programa CBERS teve início em 1988, com a assinatura do Acordo de Cooperação sobre o Satélite SinoBrasileiro de Recursos Terrestres entre a Academia Chinesa de Tecnologia Espacial (CAST) da China e o Inpe do Brasil. Já foram desenvolvidos os CBERS 1, 2, 2-B, 3, 4 e 4-A, nos quais alguns subsistemas passaram por aprimoramento tecnológico.
} 
essa participação "tardia" no projeto traz impacto para a competitividade da indústria, conforme descrito a seguir:

\begin{abstract}
"Esse projeto nasceu no IAE e serviu como base, junto dos devidos requisitos, para compor a documentação inicial para o desenvolvimento de projetos dentro das empresas. Uma questão interessante, o instituto está olhando um objeto para atender, por exemplo, um motor para aplicação, para a indústria isso não é transparente, quem irá fazer a implementação desse motor será a ICT. Não menciono isso como um problema, mas como algo que refletirá no futuro, pois houve a encomenda do governo para a ICT, porém do ponto de vista de comercialização deixa sedimentar e essa aplicação não é transparente para a empresa. Não existem perspectivas de comercialização. Isso poderia ser modificado para outras aplicações dentro do setor espacial se pensássemos, "Essa configuração de veículo lançador, é ideal? Ela é comercialmente viável?". A empresa tem ficado afastada. O relacionamento é muito específico e talvez não dê o sucesso comercial esperado, quem irá comercializar esse motor? A empresa? Para que a aplicação? Pois não será a ICT, ele tem a aplicação que entende para o Programa Espacial apenas". (Entrevista 8).
\end{abstract}

Convém, inclusive, refletir o quanto essa relação na área espacial permanece invertida, na medida em que os institutos são os demandantes às empresas (a geração da inovação sendo entendida como technology-push, um processo cumulativo de conhecimento tecnológico) e não o contrário (conceito de demand-pull, em que o mercado é o sinalizador da direção da mudança tecnológica), como era de se esperar em termos comerciais. Ou seja, as empresas deveriam ser demandantes de parcerias com as ICTs, para o desenvolvimento de novos produtos ou processo, os quais seriam encomendas do governo e da iniciativa privada.

A Entrevista 7 apresentou as vantagens que se tem ao consolidar integradoras no setor: "a indústria é mais rápida resolvendo o problema, contratando pessoas, comprando peças, fazendo consultorias e trazendo o consultor que você quiser, seja de qualquer lugar do mundo, coisas que ninguém consegue fazer no governo". Os receios dos institutos em perderem o tradicional papel de integradores perpassam pela perda (i) de poder político, (ii) da função atualmente desempenhada e, também, (iii) de orçamento.

Os interesses de cada ator são, legitimamente, diferentes: se, por um lado, as empresas querem ser incluídas nos processos de desenvolvimento, serem contratadas e, ao mesmo tempo, ganharem competitividade em nível de cadeia global de valor, por outro, os institutos querem promover o desenvolvimento científico e tecnológico. "A preocupação da ICT, é desenvolver tecnologias das quais não temos domínio soberano ainda, independente se irá vender ou não, nós não podemos na atividade espacial ficar dependendo de tecnologias que não possam ser providas. Temos que ter a capacidade de fazer quando for necessário" (Entrevista 3). Esses interesses, públicos e privados, 
claramente opostos no setor espacial fazem com que o papel do centro estratégico seja difícil, porém, extremamente relevante (MÉNARD, 2011).

Dessa forma, na medida em que as definições de tecnologias críticas são de extrema complexidade e devem considerar diferentes fatores, tais como autonomia, tempo e capacidade de desenvolvimento, competitividade industrial etc., cabe ao centro estratégico equilibrar os incentivos e controle para cada uma das partes interessadas, público e privada, ICT e empresas. A busca deve ser pelo bem maior, que é o desenvolvimento tecnológico, econômico e social a partir do Pnae, prevalecendo os interesses do bem-comum ao invés dos interesses particulares de cada parte envolvida.

\section{Conclusão}

O objetivo principal desse artigo foi analisar como a coordenação-geral da AEB no Sindae influenciou os resultados de implementação do Pnae no período de 1996 a 2018. A partir das referências técnicas e bibliográficas, das entrevistas e das análises dos materiais de pesquisa, verificou-se que a AEB enfrentou dificuldades para coordenar as ações de implementação do Pnae no período estudado. A definição da autarquia como órgão central do Sindae, tal como está no dispositivo normativo que estabelece o Sindae como arranjo institucional do setor espacial, demonstrou-se frágil e não garantiu o que o referencial utilizado na pesquisa definiu como centro estratégico.

Os motivos são variados, entre eles, a equipe reduzida, a insuficiência de capacidade estatal (tanto político-relacional, quanto técnico-burocrática), quadro orçamentário enxuto e ausência de apoio da sociedade para com o Programa Espacial Brasileiro. Os resultados são que, historicamente, os institutos apresentaram prevalência de poder e de decisões sobre a Agência, o que influenciou de forma determinante o conteúdo das missões espaciais e a limitação da participação da indústria como fornecedoras de subsistemas.

Ao longo dos anos, no entanto, os institutos têm se tornado carentes de recursos orçamentários, de infraestrutura e, em especial, de pessoal. Isso é muito grave para um setor que demanda mão de obra altamente qualificada, mas que exige longo período de formação. E, apesar dessa situação, as entidades do Sindae não vêm trabalhando na transição. Os institutos apresentam resistência em migrar o papel de integrador para as 
empresas privadas, o que se faz necessário em um contexto tecnológico e produtivo mais maduro e também resultaria em maior celeridade às entregas previstas no Pnae.

Um arranjo de implementação mais propício para gerar bons resultados seria aquele em que empresas e ICTs do setor espacial brasileiro não concorressem entre si para ocuparem o mesmo espaço ou exercerem funções semelhantes. Os institutos poderiam desenvolver outros papéis relevantes em um arranjo em que haja empresas integradoras, em especial, com foco no desenvolvimento de tecnologias estratégicas para o país, acompanhando os paradigmas tecnológicos. Em estruturas híbridas de arranjo institucional, tal como é o setor espacial, a instituição que ocupa a posição do centro estratégico deve fazer a coordenação das demais organizações, manipulando os incentivos e controles administrativos de intensidade moderada que caracterizam os híbridos. O objetivo é preservar a relação entre os agentes, evitando-se, assim, a depreciação dos ativos específicos na forma de recursos compartilhados. A AEB, como depositária de autoridade competente para monitorar as ações conjuntas, dentro de uma entidade permanente específica, que é representada pelo Sindae, não teve condições de centralizar as decisões, de estabelecer um nível de regras formais e nem de realizar o controle parcial sobre as entregas do Pnae (ou o que a literatura no caso chamou de os direitos de propriedade).

Sob a ótica da governança, e levando em conta os aspectos elencados pela literatura neste estudo, também não se mostrou eficiente a atuação da AEB. Dado o caráter da instabilidade da governança, não se observou a habilidade do Estado em alterar os arranjos de governança e dar a ele sua característica dinâmica. Ficou claro que por trás de cada equilíbrio de governança existe a intenção de diferentes atores em criar arranjos favoráveis para atingir seus propósitos específicos e tornar aqueles o mais estáveis possível, como é o caso dos institutos de pesquisa.

A decisão de se ter um Pnae robusto é política e estratégica. Deve-se ter clareza de que para o Brasil deslanchar como país que domina tecnologias espaciais e ter acesso ao espaço de forma não-dependente, é preciso convergir esforços entre organizações para propiciar tal avanço. Os interesses como nação devem ser maiores e prioritários em relação aos das instituições isoladamente. Por outro lado, a participação, o comprometimento e o empenho dessas organizações são fundamentais para o programa lograr sucesso. Ações concatenadas e convergentes entre tais instituições impactariam positivamente o setor espacial como um todo e, consequentemente, a sociedade. 
Assim, para que se tenha um arranjo de governança efetivo, capaz de resolver problemas políticos e de políticas públicas, é necessária a ocupação do papel de centro estratégico pela AEB. No entanto, a simples alteração normativa para conferir essa posição à AEB não vai garantir que o arranjo seja bem-sucedido. Dessa forma, sugere-se também que seja adotada uma nova estrutura de governança para a correção de distorções históricas, mas, mais do que isso, ela precisa trazer capacidades institucionais à AEB para uma nova forma de atuação no setor. Isso abre oportunidade para um campo de estudo dedicado às capacidades estatais necessárias. Por ora, tem-se apenas o diagnóstico de que a estrutura de arranjo institucional vigente, à luz da teoria analisada, não contribui para uma boa implementação do Pnae.

\section{Referências}

AGÊNCIA EsPACIAL BRASILEIRA (AEB). Programa Nacional de Atividades Espaciais: Pnae: 1996 - 2005. Brasília: Agência Espacial Brasileira, 1996. Disponível em: <http://www.aeb.gov.br/wpcontent/uploads/2018/07/PNAE1996.2005.pdf >. Acesso em: 26 de janeiro de 2019.

Programa Nacional de Atividades Espaciais: Pnae: 1998 - 2007. Brasília: Agência Espacial Brasileira, 1998. Disponível em: <http://www.aeb.gov.br/wpcontent/uploads/2018/07/PNAE-

1998.2007.pdf>. Acesso em: 26 de janeiro de 2019.

Programa Nacional de Atividades Espaciais: Pnae: 2005 - 2014. Brasília: Agência Espacial Brasileira, 2005. Disponível em: <http://www.aeb.gov.br/wpcontent/uploads/2018/07/PNAE-

2005.2014.pdf >. Acesso em: 26 de janeiro de 2019.

Programa Nacional de Atividades Espaciais: Pnae: 2012 - 2021. Brasília: Agência Espacial Brasileira, 2012. Disponível em: <http://www.aeb.gov.br/wpcontent/uploads/2018/05/PNAE-

Portugues.pdf $>$. Acesso em: 26 de janeiro de 2019.
Dados orçamentários da AEB. Brasília: Agência Espacial Brasileira, Diretoria de Transporte Espacial e Licenciamento, 2018a.

Dados de execução do FNDCT. Brasília: Agência Espacial Brasileira, Diretoria de Política Espacial e Investimentos Estratégicos, 2018b.

BRASIL. Decreto $\mathrm{n}^{\circ} 1.332$, de 8 de dezembro de 1994a. Disponível em: <http://www.planalto.gov.br/ccivil_03/decreto/1 990-1994/D1332.htm>. Acesso em: 24 de fevereiro de 2019.

$\begin{array}{ccc} & & \text { Decreto } \mathrm{n}^{\circ} 1.953 \text {, de } 10 \text { de julho } \\ \text { de } & \text { 1996. } & \text { Disponível em: }\end{array}$ <http://www.planalto.gov.br/ccivil 03/decreto/1 996/D1953.htm>. Acesso em: 22 de fevereiro de 2019.

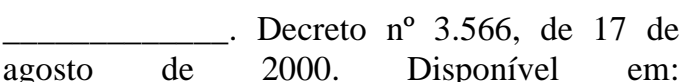
http://www.planalto.gov.br/ccivil 03/decreto/D 3566.htm\#art6. Acesso em: 22 de fevereiro de 2019.

Decreto $\mathrm{n}^{\mathrm{o}} 8.868$, de 4 de outubro de 2016. Disponível em <http://www.planalto.gov.br/ccivil_03/_ato2015 -2018/2016/decreto/D8868.htm>. Acesso em: 22 de fevereiro de 2019.

$\begin{array}{ccc} & & \text { Lei }{ }^{\circ} 8.854, \text { de } 10 \text { de fevereiro } \\ \text { de } \quad 1994 b . & \text { Disponível em: }\end{array}$ 
<http://www.planalto.gov.br/CCivil 03/LEIS/L 8854.htm>. Acesso em: 22 de fevereiro de 2019.

CÂMara dos Deputados. A política espacial brasileira. Relator: Rodrigo Rollemberg; Elizabeth Machado Veloso (coord.); Alberto Pinheiro de Queiroz Filho ... [et al.]. Brasília: Edições Câmara, 2009.

CÂMARA, Gilberto. Sobre a possível transição do modelo industrial de fabricação de satélites brasileiros, 2012.

CAPANO; HOWLETT; RAMESH (Org). Varieties of governance: dynamics, strategies and capacities. Studies in the Political Economy of Public Policy, 2015.

CARVAlHO, Himilcon. Uma análise comparativa do Programa Espacial Brasileiro. In: CÂMARA DOS DEPUTADOS. A política espacial brasileira. Relator: Rodrigo Rollemberg; Elizabeth Machado Veloso (coord.); Alberto Pinheiro de Queiroz Filho ... [ et al.]. Brasília: Edições Câmara, 2009.

DAVIS, L. E; NORTH, D.C. Institutional change and American economic growth. Cambrigde: Cambrigde University Press, 1971.

Durão, Otávio; Ceballos, Décio. Desafios estratégicos do Programa Espacial Brasileiro. In: SECRETARIA DE AsSuntos EstratéGICOS (SAE). Desafios do programa espacial brasileiro. Brasília: Presidência da República do Brasil, 2011, p. 43.

EUROCONSUlt. Relatório Executivo da Euroconsult 2018. Disponível em: $<$ http://euroconsult-ec.com/research/satellitevalue-chain-2018-extract.pdf>. Acesso em: 20 de fevereiro de 2019.

FIANI, Ronaldo. $\mathrm{O}$ enfoque moderno das instituições: estruturas de governança. In: Cooperação e conflito: instituições e desenvolvimento econômico. Rio de Janeiro. Elsevier, 2011.

Arranjos institucionais $e$ desenvolvimento: o papel da coordenação em estruturas híbridas. Texto para discussão. Ipea. Rio de Janeiro, 2013.

FUNDO MONETÁRIO INTERNACIONAL (FMI). World Economic Outlook (WEO), abril, 2020. Disponível em: <https://www.imf.org/external/datamapper/data sets/WEO>. Acesso em: 10 de setembro de 2020.
MAtos, Patrícia. Sistemas espaciais voltados para Defesa. In: ABDI \& IPEA. Mapeamento da Base Industrial de Defesa. Brasília, 2016. Disponível em: <http://www.ipea.gov.br/portal/images/stories/P DFs/livros/livros/160706_livro_mapeamento_d efesa.pdf >. Acesso em: 14 de fevereiro de 2019.

MÉNARD, Claude. Hybrid Organizations. Klein, Peter; Sykuta, Michael. The Elgar Companion to transaction cost economics, Edward Elgar, p. $176-184,2011$.

NORTH, Douglass. Custos de transação, instituições e desenvolvimento econômico. Instituto Liberal. Rio de Janeiro, 1998.

ORGANIZAÇÃO PARA A COOPERAÇÃO E DESENVOLVIMENTO ECONÔMICO (OCDE). OCDE Sience, Techonology and Industry Scoreboard 2017. OCDE Publishing 2017. Disponível em: <https://read.oecdilibrary.org/science-and-technology/oecdscience-technology-and-industry-scoreboard2017_9789264268821-en\#page1>. Acesso em: 20 de março de 2019.

OliveIRA, Mônica. A política de compras do Programa Espacial Brasileiro como instrumento de capacitação industrial. Tese de Doutorado em Engenharia e Tecnologia Espacial pelo Inpe, 2014.

SÁnchez, Tirso W. Sáenz; PAula, Maria Carlota de Souza. Desafios institucionais para o setor de ciência e tecnologia: o sistema nacional de ciência e inovação tecnológica. Parcerias estratégicas, vl. 6, n. 13 (2001). Disponível em: <http://seer.cgee.org.br/index.php/parcerias_estr ategicas/article/viewFile/203/197>. Acesso em: 20 de fevereiro de 2019.

SAntos, Bruno Vicente dos. Proposta do modelo institucional com contratantes principais para desenvolvimento e gestão de projetos espaciais no Brasil. Dissertação de Mestrado em Engenharia e Tecnologia Espaciais pelo Inpe, 2014.

SECRETARIA DE ASSUNTOS ESTRATÉGICOS (SAE). Desafios do programa espacial brasileiro. Brasília: Presidência da República do Brasil, 2011.

SATELLITE INDUSTRY ASSOCIATION (SIA). Releases 2020 SSIR. Washington, D.C., July 02, 2020. Disponível em: < https://sia.org/news- 
resources/state-of-the-satellite-industry-report/

>. Acesso em: 10 de setembro de 2020 .

SMALL, M.L. How many cases do I need? Onsience and the logic of case selection in fieldbased research. University of Chicago. 2009.

SouzA, P. N. Introdução à tecnologia de satélites: missões e segmentos. São José dos Campos: TCU. Referencial para avaliação da governança do centro de governo. Tribunal de Contas da União. Brasília: TCU, Secretaria de Controle Externo da Administração do Estado, $2016 . \quad$ Disponível em: <https://portal.tcu.gov.br/governanca/governanc apublica/centro-de-governo/>. Acesso em: $25 \mathrm{de}$ fevereiro de 2019.
VAZ, Célio da Costa. Fomento e apoio ao desenvolvimento da capacidade industrial, atendimento às demandas de fabricação de projetos espaciais. In: Brasil, Presidência da República. Secretaria de Assuntos Estratégicos. Desafios do Programa Espacial Brasileiro. Brasília: SAE, 2011.276 p.

WILLIAMSON, Oliver E. As instituições econômicas do capitalismo: firmas, mercados e relações contratuais. São Paulo: Prezco Editora, 2012.

YIN, Robert K. Estudo de caso - planejamento e métodos, $2^{\text {a }}$ edição, Porto Alegre: Bookman, 2001.

\section{Fabiany Maria Made e Vellasco}

https://orcid.org/0000-0003-2444-8566

Mestre em Governança e Desenvolvimento, pela Escola Nacional de Administração Pública (ENAP), Bacharel em Cientista Política pela Universidade de Brasília (UnB).

E-mail: fabianyvellasco@gmail.com

\section{Henrique Fernandes Nascimento}

iD https://orcid.org/0000-0003-2744-0412

Mestrando em Governança e Desenvolvimento pela Escola Nacional de Administração Pública (ENAP). Especialista em Gestão Pública. Bacharel em Ciência Política pela Universidade de Brasília (UnB).

E-mail: henriquefn@gmail.com 